\title{
Ventricular repolarization before and after treatment in patients with secondary hypertension due to renal-artery stenosis and primary aldosteronism
}

\author{
Simona Maule, Chiara Bertello, Franco Rabbia, Alberto Milan, Paolo Mulatero, Valeria Milazzo, Grazia Papotti \\ and Franco Veglio
}

A prolonged QT interval is a risk factor for ischemic heart disease in hypertensive subjects. Patients with renal-artery stenosis and primary aldosteronism (PA) are at increased risk of cardiovascular events. The objective of the present study was to evaluate the QT interval in patients with renovascular hypertension (RV) and PA before and after treatment. A total of 24 patients with RV and 38 with PA were studied; 89 patients with essential hypertension (EH) served as control group. Corrected QT intervals $($ QTcH) were measured from a 12-lead ECG. Basal QTcH was longer in RV $(429 \pm 30 \mathrm{~ms})$ and PA $(423 \pm 23 \mathrm{~ms})$ compared with EH controls $(407 \pm 18 \mathrm{~ms} ; P<0.001)$. The prevalence of $\mathrm{QTcH}>440 \mathrm{~ms}$ was higher in RV (29\%) and PA patients $(29 \%)$ compared with EH controls $(4 \% ; P<0.001)$. QTcH interval was evaluated after treatment in $19 \mathrm{RV}$ and 15 PA patients. QTcH was reduced after renal-artery angioplasty in RV patients $(419 \pm 14 \mathrm{~ms} ; P=0.02)$, and after spironolactone or adrenalectomy in PA (403 $\pm 12 \mathrm{~ms} ; P=0.01$ ). In conclusion, QT interval was prolonged in patients with RV and PA compared with controls with $E H$. After angioplasty of renal-artery stenosis in RV, and treatment with spironolactone or adrenalectomy in PA, the cardiovascular risk of such patients may be reduced by concomitant blood pressure lowering and QT duration shortening. Hypertension Research (2011) 34, 1078-1081; doi:10.1038/hr.2011.77; published online 16 June 2011

Keywords: primary aldosteronism; QT interval; renal-artery stenosis; renovascular hypertension; ventricular repolarization

\section{INTRODUCTION}

QT interval prolongation has been associated with an increased risk of ventricular arrhythmias and sudden death in the general population, ${ }^{1}$ diabetic patients ${ }^{2}$ and coronary artery disease. ${ }^{3}$ An abnormal ventricular repolarization, namely a prolonged QT interval, has been described in hypertensive patients, 4 and represents a negative prognostic factor in these patients. ${ }^{6,7}$ Patients at high risk of cardiovascular events, such as those with primary aldosteronism (PA), have been shown to have a prolonged QTc interval compared with essential hypertension $(\mathrm{EH}){ }^{8}$

Patients with renal-artery stenosis are at increased risk of cardiovascular events. ${ }^{9}$ The causes are uncertain and may be related to renal insufficiency, renin-angiotensin-aldosterone and sympathetic nervous system activation and coronary atherosclerosis. ${ }^{10,11}$

The aim of the present study was to evaluate the QT interval in patients with renovascular hypertension (RV), before and after endovascular revascularization (balloon renal-artery angioplasty with or without stenting), and in patients with PA, before and after treatment with spironolactone (bilateral adrenal hyperplasia) or adrenalectomy (aldosterone-producing adenoma).

\section{METHODS}

Patients with RV were recruited according to the following characteristics: consecutive patients referred to our Unit from 2002 to 2009 with hypertension with evidence of a hemodynamically significant renal-artery stenosis at duplex ultrasonography, and recurrent congestive heart failure, progressive renal failure, uncontrolled or refractory hypertension, which indicated a revascularization procedure. ${ }^{12}$

Patients with PA were recruited according to the following characteristics: consecutive patients referred to our Unit from 2002 to 2009 with an aldosterone to plasma renin activity ratio (aldosterone-renin ratio) $>40$, together with aldosterone levels $>15 \mathrm{ng} \mathrm{dl}^{-1}, 13$ underwent further evaluation with a salt loading test ( 21 of $0.9 \% \mathrm{NaCl}$ infused over $4 \mathrm{~h}$ ). ${ }^{14}$ Plasma aldosterone levels $>5 \mathrm{ng} \mathrm{dl}^{-1}$ at the end of the test were deemed diagnostic for PA. These patients eventually underwent adrenal CT scan with fine cuts and adrenal vein sampling. Sampling was considered successful if the adrenal vein/inferior vena cava gradient was at least 2. Lateralization was diagnosed when the aldosterone/ cortisol ratio from the adrenal was at least four times the ratio from the other adrenal gland. ${ }^{13}$

A total of 60 and 160 hypertensive patients were diagnosed with RV and PA, respectively. After exclusion of patients with arrhythmias, bundle branch blocks, diabetes, obesity (body mass index $\geqslant 30$ ) and those taking antiarrhythmic drugs of any class, 24 patients with RV (14 fibromuscular dysplasia and 10 atherosclerotic 
renal-artery disease) and 38 patients with PA (29 bilateral adrenal hyperplasia and 9 aldosterone-producing adenoma) were included in the study.

Simultaneous, 12-lead ECGs were recorded by means of a 12-channel ECG (Mac 1200, Marquette Hellige, Freiburg, Germany) at a paper speed of $50 \mathrm{~mm} \mathrm{~s}^{-1}$, between 9:00 and 11:00 a.m. RR and QT intervals were measured with a magnifying ruler on the ECG tracing. QT interval was taken from the beginning of the QRS complex to the end of the downslope of the T wave (crossing of the isoelectric line). When $\mathrm{T}$ waves were inverted, the end was taken at the point where the trace returned to the isoelectric line. When $U$ waves were present, the end of the $T$ wave was taken as the nadir between the $T$ and the $U$ wave. If the end of the T wave was not clearly identifiable, the lead was not included in the analysis. Only ECGs with six or more total leads and three or more precordial leads with measurable QT intervals were considered. In each lead, three consecutive beats in the period of minimal RR variation were considered for QT measurement. The mean value of these three intervals was calculated. The QT considered for each subject was the maximum QT measured in any lead. QT intervals were corrected for the previous cardiac cycle length according to Hodges' formula: QTcH $(\mathrm{ms})=\mathrm{QT}+1.75$ (heart rate-60). ${ }^{15} \mathrm{QTcH}$ was considered prolonged when $>440 \mathrm{~ms}$, in accordance with the criteria commonly used in the literature.

QT analysis was performed by the same independent operator (M.S.), who was unaware of the clinical data of patients and controls. Twelve randomly chosen ECGs (six RV and six PA) were analysed by the same observer on two different occasions, 1 week apart. Intra-observer variability in QT measurements was evaluated with Bland and Altman's plot method. The mean of the difference for QTcH was $0.38 \mathrm{~ms}$ (1.96 s.d.: 1.86), the corresponding $95 \%$ confidence intervals ranging from -0.25 to $1.51 \mathrm{~ms}$.

A second observer (V.M.), unaware of the clinical data of the patients, measured QT intervals from 50 randomly chosen ECGs. The inter-observer coefficient of variation for the QT interval, calculated to assess reproducibility, was $3.4 \%$.

In RV patients, ECG recordings were performed before and after revascularization. Balloon angioplasty was performed in 19 patients $(41 \%$ without stenting and 59\% with stenting). The average time between ECG measurements was $19 \pm 25$ months. Angioplasty did not result in procedure-related complications or re-stenosis in any of the patients.

In PA patients, ECG recordings were performed before and after treatment with spironolactone (10 patients with bilateral adrenal hyperplasia) or surgery (five patients with aldosterone-producing adenoma). The average time between ECG measurements was $25 \pm 25$ months.

Results were compared with those of 89 sex- and age-matched controls with EH.

All patients and controls gave their fully-informed consent and the local Ethics Committee approved the study.

Statistical analysis was performed using SPSS Statistics 17.0 (IBM Italia, Milano, Italy) and Stata 11 packages (TStat S.r.l., Sulmona (AQ), Italy). Results were expressed as means \pm s.d. Wilcoxon's test for paired data was used to compare group distributions, and $\chi^{2}$-test was used to test for group differences of proportions. Multiple linear regression analysis was performed using QTcH as dependent variable. Analysis of covariance was performed to verify if the mean difference in QTc duration between secondary and EH patients would remain significant after adjustments for gender, blood pressure, left ventricular hypertrophy, serum potassium and antihypertensive treatment. A $P$-value $<0.05$ was considered statistically significant.

\section{RESULTS}

General and clinical characteristics of the study population are shown in Table 1. Compared with EH, RV patients had higher blood pressure values, greater prevalence of left ventricular hypertrophy and a higher number of antihypertensive drugs $(P<0.001)$; PA patients showed higher aldosterone-renin ratio and lower plasma renin activity and potassium levels $(P<0.001)$.

Results of QTcH and RR intervals are shown in Table 2. Compared with $\mathrm{EH}, \mathrm{RV}$ and PA patients showed longer $\mathrm{QTcH}$ values $(P<0.001)$. The prevalence of QTcH $>440 \mathrm{~ms}$ was higher in RV $(29 \%)$ and PA patients $(29 \%)$ compared with $\mathrm{EH}$ controls $(4 \% ; P<0.001$ among
Table 1 General and clinical characteristics of the study population

\begin{tabular}{|c|c|c|c|c|}
\hline & $\begin{array}{l}\text { Renovascular } \\
\text { hypertension } \\
(n=24)\end{array}$ & $\begin{array}{c}\text { Primary } \\
\text { aldosteronism } \\
(\mathrm{n}=38)\end{array}$ & $\begin{array}{c}\text { Essential } \\
\text { hypertension } \\
(\mathrm{n}=89)\end{array}$ & $P$ \\
\hline Age (years) & $54 \pm 17$ & $52 \pm 9$ & $51 \pm 8$ & 0.42 \\
\hline Male sex (\%) & 37 & 60 & 53 & 0.20 \\
\hline \multicolumn{5}{|l|}{ Therapy (\%) } \\
\hline Ca-channel blockers & 62 & 81 & 36 & $<0.001$ \\
\hline ACE-inhibitors & 38 & 16 & 23 & 0.16 \\
\hline AIIRA & 48 & 38 & 42 & 0.76 \\
\hline$\alpha 1$-blockers & 28 & 40 & 6 & $<0.001$ \\
\hline Diuretics & 28 & 3 & 13 & 0.02 \\
\hline $\begin{array}{l}\text { Daily antihypertensive } \\
\text { agents }(n)\end{array}$ & $2.1 \pm 1.0$ & $1.8 \pm 0.7$ & $1.2 \pm 0.9$ & $<0.001$ \\
\hline $\mathrm{SBP}(\mathrm{mm} \mathrm{Hg})$ & $161 \pm 20$ & $151 \pm 21$ & $137 \pm 16$ & $<0.001$ \\
\hline $\mathrm{DBP}(\mathrm{mm} \mathrm{Hg})$ & $93 \pm 12$ & $94 \pm 12$ & $83 \pm 10$ & $<0.001$ \\
\hline $\begin{array}{l}\text { Plasma aldosterone } \\
\left(\mathrm{ng} \mathrm{dl}^{-1}\right)\end{array}$ & $35.6 \pm 28.4$ & $35.6 \pm 19.9$ & $19.7 \pm 11.7$ & 0.001 \\
\hline PRA (ng ml $\left.{ }^{-1} \mathrm{~h}^{-1}\right)$ & $12.8 \pm 15.2$ & $0.31 \pm 0.22$ & $5.30 \pm 7.22$ & $<0.001$ \\
\hline ARR & $15.5 \pm 21.7$ & $166.2 \pm 127.8$ & $12.5 \pm 12.3$ & $<0.001$ \\
\hline Potassium (mequiv ${ }^{-1}$ ) & $4.4 \pm 0.3$ & $3.6 \pm 0.7$ & $4.3 \pm 0.3$ & $<0.001$ \\
\hline LVH (\%) & 59 & 51 & 16 & $<0.001$ \\
\hline
\end{tabular}

Abbreviations: AlIRA, angiotensin-II receptor antagonists; ARR, aldosterone to PRA ratio; DBP, diastolic blood pressure; LVH, left ventricular hypertrophy, PRA, plasma renin activity; SBP, systolic blood pressure.

$P$, statistical significance among the three groups; LVH, evaluated with echocardiography, defined as left ventricular mass index $>125 \mathrm{~g} \mathrm{~m}^{-2}$ for males and $>110 \mathrm{~g} \mathrm{~m}^{-2}$ for females.

Table 2 Results of QTcH and RR intervals in the study population

\begin{tabular}{ccccc}
\hline & $\begin{array}{c}\text { Renovascular } \\
\text { hypertension } \\
(\mathrm{n}=24)\end{array}$ & $\begin{array}{c}\text { Primary } \\
\text { aldosteronism } \\
(\mathrm{n}=38)\end{array}$ & $\begin{array}{c}\text { Essential } \\
\text { hypertension } \\
(\mathrm{n}=89)\end{array}$ & $\mathrm{P}^{a}$ \\
\hline QTcH (ms) & $429 \pm 30$ & $423 \pm 23$ & $407 \pm 18$ & $<0.001$ \\
Males & $412 \pm 21$ & $421 \pm 23$ & $402 \pm 18$ & \\
Females & $439 \pm 30$ & $427 \pm 23$ & $412 \pm 18$ & \\
$P^{b}$ & 0.02 & 0.44 & 0.006 & \\
RR (ms) & $889 \pm 123$ & $895 \pm 137$ & $861 \pm 151$ & 0.41
\end{tabular}

Abbreviation: QTcH, QT interval corrected according to Hodge's formula.

astatistical significance among the three groups.

bstatistical significance between sexes.

groups). Patients with RV due to fibromuscular dysplasia had a QTcH similar to those with atherosclerotic renal-artery disease $(436 \pm 28$ vs. $432 \pm 32 \mathrm{~ms}$, respectively, $P=0.78$ ). Patients with $\mathrm{PA}$ due to aldosterone-producing adenoma showed a slightly more prolonged QTcH compared with those with bilateral adrenal hyperplasia ( $438 \pm 24$ vs. $419 \pm 21 \mathrm{~ms}$, respectively, $P=0.06$ ).

Multiple linear regression analysis, using QTcH as dependent variable, was performed in all patients. The following independent factors were entered into the model: age, sex, systolic blood pressure, left ventricular hypertrophy, serum potassium, and the use of Ca-channel blockers, angiotensin converting enzyme inhibitors, angiotensin II receptor antagonists, $\alpha 1$-blockers and diuretics. The analysis identified sex $(\beta=0.226, P=0.01)$ and the use of Ca-channel blockers $(\beta=0.335, P=0.001)$ as independent predictors of $\mathrm{QTcH}$, while age $(\beta=-0.064, P=0.48)$, systolic blood pressure $(\beta=-0.017$, $P=0.86)$, left ventricular hypertrophy $(\beta=0.099, \quad P=0.32)$, serum potassium $(\beta=-0.067, \quad P=0.47)$, angiotensin converting enzyme inhibitors $(\beta=0.069, P=0.50)$, angiotensin II receptor antago- 


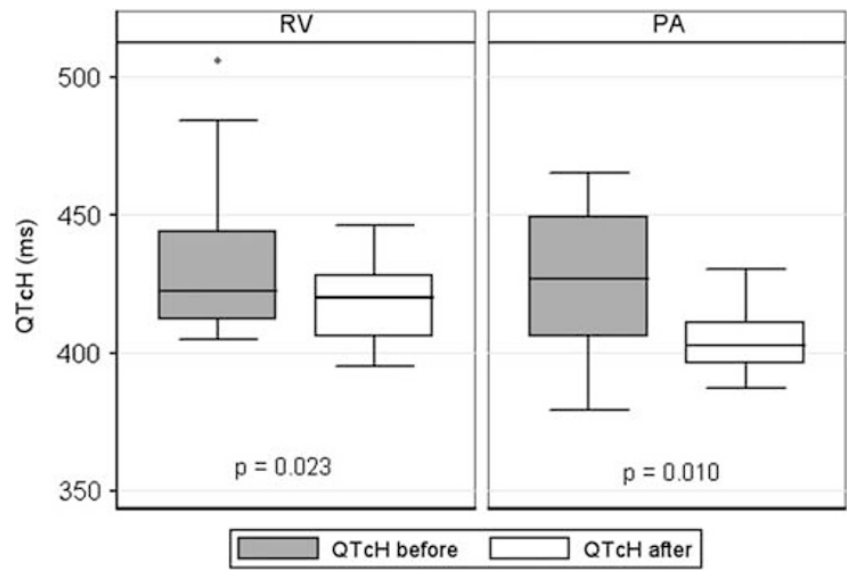

Figure 1 Results of QTcH interval before and after treatment. PA, primary aldosteronism; RV, renovascular hypertension.

nists $(\beta=0.000, P=0.99), \alpha 1$-blockers $(\beta=0.110, P=0.23)$ and diuretics $(\beta=0.087, P=0.34)$ were not significantly related to QTcH length. With the limits of the small subpopulation size, the statistical significance for the above variables was not maintained if multiple linear regression analysis, using QTcH as dependent variable, was performed separately in each subgroup of patients.

Analysis of covariance was performed. After adjustments for sex, systolic blood pressure, left ventricular hypertrophy, serum potassium and antihypertensive treatment, the difference in QTcH between subgroups was maintained ( $P=0.032$ for the type of hypertension, $\mathrm{RV}, \mathrm{PA}$ and $\mathrm{EH})$.

After treatment, QTcH interval was significantly reduced in patients with RV $(P=0.02)$ and PA $(P=0.01)$, as shown in Figure 1. Reductions of QTcH duration were similar in RV and PA patients $(-2.8 \pm 4.7$ and $-4.8 \pm 5.4 \%$ change, respectively; $P=0.18$ ); compared with basal values, the prevalence of QTcH $>440 \mathrm{~ms}$ was reduced to $12 \%$ in RV and $0 \%$ in PA patients after treatment.

After treatment, blood pressure was significantly lower in both the groups of patients (RV: before $161 \pm 20 / 93 \pm 11 \mathrm{~mm} \mathrm{Hg}$, after $138 \pm 18 / 83 \pm 7 \mathrm{~mm} \mathrm{Hg}, \quad P<0.005$; PA: before $155 \pm 19$ / $96 \pm 10 \mathrm{~mm} \mathrm{Hg}$, after $129 \pm 10 / 80 \pm 9 \mathrm{~mm} \mathrm{Hg}, P<0.0001)$.

\section{DISCUSSION}

The present study evaluated the ventricular repolarization in patients with RV hypertension. QT intervals of RV patients were prolonged compared with subjects with $\mathrm{EH}$, and similar to those of subjects with PA. In both RV and PA patients, after specific treatments, QTcH duration shortened and prevalence of prolonged QTcH values fell, together with a decline in blood pressure levels.

RV and PA patients in the present study showed higher blood pressure values and greater prevalence of left ventricular hypertrophy, and an increased number of antihypertensive medications per day, compared with the control group. Such results confirmed a severe hypertensive status with a high cardiovascular risk in RV and PA patients, ${ }^{16}$ compared with $\mathrm{EH}$.

The evaluation of ventricular repolarization in RV patients has been addressed for the first time in the present study. The only other data available in the literature are those of RV patients used as a control group in a study on myocardial repolarization lability in individuals with high-normal blood pressure. ${ }^{17}$ In keeping with our results, these authors described an increased QT interval variability index compared with subjects with high-normal blood pressure.
The mechanisms behind the abnormal ventricular repolarization of RV patients are not known. Factors such as hyperactivity of the sympathetic nervous system, and abnormality of intracellular ion currents and couplings may have a role in QT prolongation. ${ }^{18,19}$ Data from animal studies show that RV hypertension induces a prolongation of the activation-recovery interval on the epicardium of both ventricles. ${ }^{20}$ The mechanisms of the repolarization prolongation have been related to angiotensin II and aldosterone. Angiotensin II inhibits potassium currents in cardiac myocytes both directly, through modulation of Kir2.1-Kir2.2 channel subunit expression and inward rectifier potassium (IK1) currents, ${ }^{21}$ and indirectly, by increasing aldosterone production. Aldosterone has been shown to increase acutely action potential duration in humans. ${ }^{22}$ Treatment with losartan normalizes ventricular alterations (assessed by ventricular fibrillation threshold, dispersion of effective refractory periods, action potential duration and IK1 current density) in renovascular hypertensive rats. ${ }^{23}$

QT interval prolongation in PA patients has been demonstrated by our group in a previous study. ${ }^{8} \mathrm{ARR}$ and systolic blood pressure were found to be independent predictors of QTC.

Causes of QT interval prolongation in PA include the depletion of intracellular potassium concentration because of elevated aldosterone levels, the presence of a more advanced hypertensive heart disease, aldosterone-induced myocardial fibrosis and the presence of a chronic activation of the sympathetic nervous system. ${ }^{8}$

The assessment of ventricular repolarization in hypertensive patients is important in terms of prognosis. A prolonged QT interval is a risk factor for ischemic heart disease in hypertensive subjects, ${ }^{6}$ and in EH with left ventricular hypertrophy QT interval duration is independently associated with an increased risk of cardiovascular and all-cause mortality, even after effective antihypertensive treatment. ${ }^{4}$

Multiple linear regression analysis identified the use of Ca-channel blockers as an independent predictor of QTcH length. Both RV and PA patients and $\mathrm{EH}$ controls in treatment with Ca-channel blockers showed a longer QTcH interval (data not shown). Nevertheless, none of the Ca-channel blockers employed has been associated with QT prolongation (http://www.qtdrugs.org). In the literature, the use of calcium antagonists is associated with no effect $^{24}$ or amelioration ${ }^{25}$ of ventricular repolarization, and the result of the present study may depend on the prescription of such agents in the more severe cases of hypertension.

After specific treatments (renal-artery revascularization in $\mathrm{RV}$, spironolactone in PA with bilateral adrenal hyperplasia, or adrenalectomy in PA with aldosterone-producing adenoma), QTc duration shortened and the prevalence of prolonged QTc interval was reduced. The causes of these modifications cannot be addressed within the present study. It is possible that the cardiac benefit of the improved ventricular repolarization may be dependent on the decline in blood pressure levels or the reduction of the activity of the sympathetic nervous system. ${ }^{11}$

In RV patients, the effects of revascularization on ventricular repolarization had not been addressed before. After adrenalectomy, QT intervals shorten in patients with Conn's adenoma. ${ }^{26}$ The effect of drug therapy on QT interval in PA had not been studied before, although aldosterone-blockers were shown to improve QT dispersion in patients with heart failure, ${ }^{27}$ and reduce the risk of sudden death from cardiac causes in severe heart failure ${ }^{28}$ and after myocardial infarction. $^{29}$

A limitation of the study was the small number of RV patients. This is due to a selection bias imposed by the strict pharmacological inclusion criteria and the low prevalence of clinically manifested RV 
hypertension (1-5\% of hypertensive patients). ${ }^{11,30}$ The strict selection of patients and the short follow-up period may also account for the reduction in blood pressure after angioplasty, a result that is in contrast with those of two large published trials. ${ }^{31,32}$

In conclusion, patients with secondary hypertension due to renalartery stenosis and PA have a prolonged QT interval compared with subjects with EH. Ventricular repolarization improves after specific treatments of the two conditions. Whether QT prolongation worsens the prognosis of these patients has yet to be established.

\section{CONFLICT OF INTEREST}

The authors declare no conflict of interest.

1 Straus SM, Kors JA, De Bruin ML, van der Hooft CS, Hofman A, Heeringa J, Deckers JW, Kingma JH, Stukenboom MC, Stricker BH, Witteman JC. Prolonged QTc interval and risk of sudden cardiac death in a population of older adults. J Am Coll Cardiol 2006; 47: 362-367.

2 Stettler C, Bearth A, Allemann S, Zwahlen M, Zanchin L, Deplazes M, Christ ER, Teuscher A, Diem P. QTC interval and resting heart rate as long-term predictors of mortality in type 1 and type 2 diabetes mellitus: a 23-year follow-up. Diabetologia 2007; 50: 186-194.

3 Chug SS, Reinier K, Singh T, Uy-Evanado A, Socoteanu C, Peers D, Mariani R, Gunson $\mathrm{K}$, Jui J. Determinants of prolonged QT interval and their contribution to sudden death risk in coronary artery disease: the Oregon Sudden Unexpected Death Study. Circulation 2009; 119: 663-670.

4 Oikarinen L, Neiminen MS, Viitasalo M, Toivonen L, Jern S, Dahlof B, devereux RB, Okin PM, LIFE Study Investigators. QRS duration and QT interval predict mortality in hypertensive patients with left ventricular hypertrophy. The losartan intervention for endpoint reduction in hypertension study. Hypertension 2004; 43: 1029-1034.

5 Kulan K, Ural D, Komsuoglu B, Agacdiken A, Goldeli O, Komsuoglu SS. Significance of QTc prolongation on ventricular arrhythmias in patients with left ventricular hypertrophy secondary to essential hypertension. Int J Cardiol 1998; 64: 179-184.

6 Schillaci G, Pirro M, Ronti T, Gemelli F, Pucci G, Innocente S, Porcellati C, Mannarino E. Prognostic impact of prolonged ventricular repolarisation in hypertension. Arch Intern Med 2006; 166: 909-913.

7 Salles GF, Cardoso CR, Muxfeldt ES. Prognostic value of ventricular repolarization prolongation in resistant hypertension: a prospective cohort study. J Hypertens 2009; 27: 1094-1101.

8 Maule S, Mulatero P, Milan A, Leotta G, Caserta M, Bertello C, Rabbia F, Veglio F. QT interval in patients with primary aldosteronism and low-renin essential hypertension. J Hypertens 2006; 24: 2459-2464.

9 Conlon PJ, Little MA, Pieper K, Mark DB. Severity of renal vascular disease predicts mortality in patients undergoing coronary angiography. Kidney Int 2001; 60: 1490-1497.

10 Uzu T, Inoue T, Fuji T, Nakamura S, Inenaga T, Yutani C, Kimura G. Prevalence and predictors of renal-artery stenosis in patients with myocardial infarction. Am J Kidney Dis 1997; 29: 733-738.

11 Dworkin LD, Cooper CJ. Renal-artery stenosis. N Engl J Med 2009; 361: 1972-1978.

12 Hirsch AT, Haskal ZJ, Hertzer NR, Bakal CW, Creager MA, Halperin JL, Hiratzka LF, Murphy WR, Olin JW, Puschett JB, Rosenfield KA, Sacks D, Stanley JC, Taylor Jr LM, White CJ, White J, White RA, Antman EM, Smith Jr SC, Adams CD, Anderson JL, Faxon DP, Fuster V, Gibbons RJ, Hunt SA, Jacobs AK, Nishimura R, Ornato JP, Page RL, Riegel B. ACC/AHA 2005 practice guidelines for the management of patients with peripheral arterial disease (lower extremity, renal, mesenteric, and abdominal aortic). Circulation 2006; 113: e463-e654.
13 Mulatero P, Stowasser M, Loh KC, Fardella CE, Gordon RD, Mosso L, Gomez-Sanchez $\mathrm{CE}$, Veglio F, Young Jr WF. Increased diagnosis of primary aldosteronism, including surgically correctable forms, in centers from five continents. J Clin Endocrinol Metab 2004; 89: 1045-1050.

14 Luo S, Michler K, Johnston P, Macfarlane PW. A comparison of commonly used QT correction formulae: the effect of heart rate on the QTC of normal ECGs. J Electrocardiol 2004; 37 (suppl): 84-90.

15 Holland OB, Brown H, Kuhnert L, Fairchild C, Risk M, Gomez-Sanchez CE. Further evaluation of saline infusion for the diagnosis of primary aldosteronism. Hypertension 1984; 6: 717-723.

16 Losito A, Fagugli RM, Zampi I, Parente B, de Rango P, Giordano G, Cao P. Comparison of target organ damage in renovascular and essential hypertension. Am J Hypertens 1996; 9: 1062-1067.

17 Myredal A, Gao S, Friberg P, Jensens G, Larsson L, Johansson M. Increased myocardial repolarisation lability and reduced cardiac baroreflex sensitivity in individuals with high-normal blood pressure. J Hypertens 2005; 23: 1751-1756.

18 Petersson MJ, Rundqvist B, Johansson M, Eisenhofer G, Lambert G, Herlitz $H$, HensenG, Friberg P. Increased cardiac sympathetic drive in renovascular hypertension. J Hypertens 2002; 20: 1181-1187.

19 Marfella R, Rossi F, Giugliano D. Hyperglycemia and QT interval: time for re-evaluation. Diabetes Nutr Metab 2001; 14: 63-65.

20 Krandycheva VV, Kharin SN, Azarov JE, Shmakov DN. The effects of renovascular hypertension on repolarization of ventricular epicardium. Exp Clin Cardiol 2009; 14: e51-e56.

21 Domenighetti AA, Boixel C, Cefai D, Abriel H, Pedrazzini T. Chronic angiotensin II stimulation in the heart produces an acquired long QT syndrome associated with IK1 potassium current downregulation. J Mol Cell Cardiol 2007; 42: 63-70.

22 Tillmann HC, Schumacher B, Yasenyev O, Junker M, Christ M, Feuring M, Wehling M. Acute effects of aldosterone on intracardiac monophasic action potentials. Intern $\mathrm{J}$ Cardiol 2002; 84: 33-39.

23 Rials SJ, Xu X, Wu Y, Liu T, Marinchack RA, Kowley PR. Restoration of normal ventricular electrophysiology in renovascular hypertensive rabbits after treatment with Iosartan. J Cardiovasc Pharmacol 2001; 37: 317-323.

24 Porthan K, Viitasalo M, Hiltunen TP, Vaananen H, Dabek J, Suonsyrja T, Hannila-Handelberg T, Virolainen J, Nieminen MS, Toivonen L, Kontula K, Oikarinen L. Short-term electrophysiological effects of losartan, bisoprolol, amlodipine, and hydrochlorothiazide in hypertensive men. Ann Med 2009; 41: 29-37.

25 Takahara A, Nakamura Y, Wagatsuma H, Aritomi S, Nakayama A, Satoh Y, Akie Y, Sugiyama A. long-term blockade of $\mathrm{L} / \mathrm{N}$-type $\mathrm{Ca}(2+)$ channels by cilnidipine ameliorates repolarization abnormality of the canine hypertrophied heart. $\mathrm{Br} J$ Pharmacol 2009; 158: 1366-1374.

26 Matsumura K, Fujii K, Kansui Y, Arima H, lida M. Prolongation of the QT interval in primary aldosteronism. Clin Exp Pharmacol Physiol 2005; 32: 66-69.

27 Yee KM, Pringle SD, Struthers AD. Circadian variation in the effect of aldosterone blockade on heart rate variability and QT dispersion in congestive heart failure. J Am Coll Cardiol 2001; 37: 1800-1807.

28 Pitt B, Zannad F, Remme WJ, Cody R, Castaigne A, Perez A, Palensky J, Wittes J. The effect of spironolactone on morbidity and mortality in patients with severe heart failure. N Engl J Med 1999; 341: 709-717.

29 Pitt B, Remme WJ, Zannad F, Neaton J, Martinez F, Roniker B, Bittman R, Hurley S, Kleiman J, Gatlin M. Eplerenone, a selective aldosterone blocker, in patients with left ventricular dysfunction after myocardial infarction. N Engl J Med 2003; 348: 1309-1321.

30 Shetty R, Amin MS, Jovin IS. Atherosclerotic renal artery stenosis: current therapy and future developments. Am Heart J 2009; 158: 154-162.

31 The ASTRAL Investigators. Revascularization versus medical therapy for renal-artery stenosis. N Engl J Med 2009; 361: 1953-1962.

32 Bax L, Woittiez AJ, Kouwenberg HJ, Mali WP, Buskens E, Beek FJ, Braam B, Huysmans FT, Schultze Kool LJ, Rutten MJ, Doorenbos CJ, Aarts JC, Rabelink TJ, Plouin PF, Raynaud A, van Montfrans GA, Reekers JA, van den Meiracker AH, Pattynama PM, van de Ven PJ, Vroegindeweij D, Kroon AA, de Haan MW, Postma CT, Beutler JJ. Stent placement in patients with atherosclerosic renal artery stenosis and impaired renal function: a randomized trial. Ann Intern Med 2009; 150: 840-848. 